\title{
THEORETICAL AND EXPERIMENTAL APPROACH of Multi-Phase Composite Materials
}

\author{
Curtu, I. \& Motoc LuCA, D.
}

Abstract: The herein contribution concerns on theoretical and experimental approaches of the effective elastic moduli of multi-phase, fibre and particles, polymeric composites materials from micromechanics theoretical point of view vs. experimental retrieved values. A homogenization concept will be presented in order to predict the effective elastic moduli of this class of composite materials, based on different theories and experimental research on samples made from glass fibres and different types of particles (metallic, ceramic) embedded in different volume fraction into a polymeric matrix. The experimental values were compared with the theoretical ones in order to size the influencing factors on the effective elastic moduli. The experiments were carried on samples at room temperature and on samples subjected to different post-curing temperature cycles (tensile, compression and bending).

Key words: micromechanics, multiphase, composite, materials, characterization
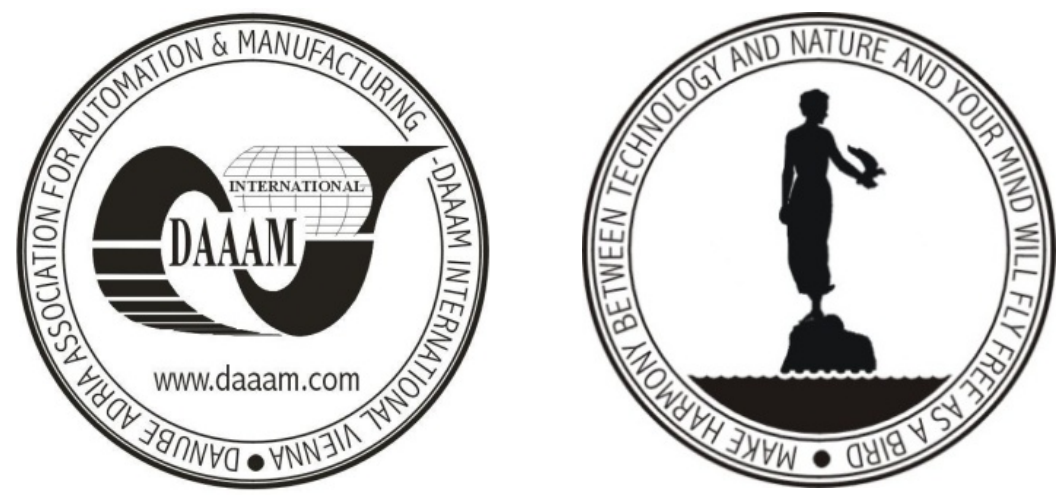

Authors' data: Prof. Dipl. -Ing. Curtu, I[oan]; Assoc. Prof. Dipl.-Ing. Dr. Motoc Luca, D[ana], Transilvania University of Brasov, 29 Eroilor Av., 500107, Brasov, Romania,curtui@unitbv.ro,danaluca@unitbv.ro

This Publication has to be referred as: Curtu, I[oan] \& Motoc Luca, D[ana] (2009). Teoretical and ExperimentalApproach of Multi-Phase Composite Materials, Chapter 37 in DAAAM International Scientific Book 2009, pp. 349-362, B. Katalinic (Ed.), Published by DAAAM International, ISBN 978-3-901509-69-8, ISSN 1726-9687, Vienna, Austria

DOI: $10.2507 /$ daaam.scibook.2009.37 